\title{
Gender and Age as Variables in Marriages in Albania during Transition
}

\author{
Esmeralda Xheraj
}

PhD candidate, European University of Tirana

\section{Doi:10.5901/ajis.2015.v4n1p205}

\begin{abstract}
The article "Gender and age as variables in marriages in Albania during the transition" analyzes the dynamics and impact of gender and age in marriages in Albania after the 1990's until today. The political, economic and social changes that took place in Albania after 1990 have had and continue to have a significant impact in typologies and FENOMENOLOGJINË of marriages and in the role and functions of the Albanian family. The marriage age for women is increasing, mainly for the same reasons that the marriage age for men is increasing. The age difference between women and men is increasing in correlation with the process of urbanization, social development, social emancipation as well as the contact with other cultures and communities. The age difference between spouses is inversely correlated with their level of education. The establishment of marriages and the creation of families have changed, therefore there is a need for changes in the social, gender and health policies of the country.
\end{abstract}

Keywords: Marital relations, family, tranzition, age differences, gender differences, educational differences, motherhood, birth rates.

\section{Introduction}

In 1990, there was an increase in marriage rates in Albania. The high marriage rates, especially before 1990, have brought changes in the typology of marriage. Kjo tipologji mund të mos ketë respektuar në mënyrë rigoroze standartet e një periudhe të qetë. Marital ties, are not influenced by the political developments, however are not completely independent of them. Moreover, because of the dramatic changes in the Albanian society in the last decade of the last century and the liberalization of social relations, new typologies of marriages were created. Marital ties gradually began to overcome the barriers arising from the politization of human relations. Relationships, banned to get married due to the political status of the lovers, started to overcome these restrictions. The restructuring of society was followed by other people's relatonships with previous values, standards and ideological taboos. In some cases this process was passive, while in other cases as a precaution to future developments. In one way or another, the changing attitudes toward marriage, was also imposed by the policy pursued during the first years of transition. This attitude highlited people's origin and political status. Expectations of people as elements of this treatment can be continued even in a democratic society did not come entirely wrong. Then difference between former privileged and politically persecuted people, former communists and anticommunist, etc. produced actions that led to the establishment of marriages. The international migration of Albanians has also had an impact in the changes of marriage typology. (Barjaba, 20011b)

\section{Marriage Indicators during the Transition}

The above social prophylaxis was a political protection against the unfair treatment of people, a characteristic of undemocratic society. This is understandable. In a society where people's status was determined based on political parameters or their past, it is no wonder that spouses, as well as directors were also elected on the same criteria. The old mentality related to politicization of human relations also partly influenced the family realtions. This circumstance led to homogamy, marriages between individuals with close social distance (Girard, 1974). This trend is fading in the last two decades of the transition.

The table below provides an overview of some indicators of marriages performed in 1990. 
Table 1: Marriages according to gender and age group, 1990.

\begin{tabular}{|l|l|c|c|c|}
\hline \multirow{2}{*}{ Age group of grooms } & \multicolumn{5}{|c|}{ Age group of brides } \\
\cline { 2 - 5 } & Total & 24 Years Old & $\mathbf{2 5 - 3 4}$ Years Old & 35+ Years Old \\
\hline-24 & 8752 & 8019 & 713 & 20 \\
\hline $25-34$ & 18853 & 14134 & 4168 & 101 \\
\hline $35+$ & 1387 & 186 & 795 & 306 \\
\hline Total & 28992 & 22429 & 5676 & 427 \\
\hline
\end{tabular}

Source: Statistical Yearbook of Albania, INSTAT 1991. (Processed data)

During 1990, men in the age group up to 24 years old married women of the same age group. Only 8.4 percent marriaed older women. Among the 8.4 percent group, less than 3 percent married women older than 35 years. About 90 percent of marriages in this age group were marriages between men and women of the same age group. This is explained by the close contact that the young adults have with each other due to common education and social environment.

The analysis of marriages of men between the ages of 25-34 shows two features: the majority of men marry women younger than 24 years old and a small group of them marry women of the same age group, 25-34. This shows that Albanian women consider the age of 24 or younger as the ideal age to get married. In 1990, this opinion was held by 77.4 percent of women. Finding a partner of the same age is becoming less common. For women younger than 24 years old this indicator was about 91.6 percent, while for the age group 25-34 it drops to 24.5 percent. For the age group over 35 this indicator is even lower: 22 percent.

The indicators regarding the tendency of men marrying older women for each age group are as following: 8.4 percent for the age group younger than 24 years old, 0.5 percent for the age group 24-35 years; while for the age group 36-45 years this indicator is negligible. The tendency of men marrying older women is inversely proportional to their age. Given the albanian tradition that brides should be younger that grooms, the most common "outliers" of this tradition are men younger than 24 years old.

The above tradition was better followed by men aged over 35 years, 78 percent of whom married in 1990, preferred to marry younger women.

\section{Marriages under the Pressure of Political and Social Change}

Over the years men are becoming more and more demanding in choosing their wives.

Table 2: The age difference between spouses. Percent distribution of married women at age 20-24 by the age difference with their spouse or partner, and by background characteristics, Albania 2008-2009.

\begin{tabular}{|c|c|c|c|c|c|c|}
\hline \multicolumn{5}{|c|}{$\begin{array}{l}\text { The percentage of currently married women } \\
\text { aged 20-24 whom their spouse/ partner is: }\end{array}$} & \multicolumn{2}{|c|}{$\begin{array}{l}\text { The number of currently married } \\
\text { women aged } 20-24\end{array}$} \\
\hline & less tl & $\operatorname{an} 0-4 y$ & years > & $>5-9$ years & $s>10+$ years & Total \\
\hline \multicolumn{7}{|l|}{ Characteristics } \\
\hline Urban & 3.1 & 31.5 & 39.5 & 25.9 & 100.0 & 122 \\
\hline Rural & 0.4 & 38.0 & 38.9 & 22.6 & 100.0 & 235 \\
\hline \multicolumn{7}{|l|}{ Region } \\
\hline Coastal & 1.0 & 30.2 & 37.1 & 31.7 & 100.0 & 110 \\
\hline Central & 0.0 & 38.6 & 41.5 & 20.0 & 100.0 & 181 \\
\hline Mountain & 3.2 & 40.9 & 37.9 & 18.0 & 100.0 & 37 \\
\hline Urban Tirana & $(8.1)$ & $(33.1)$ & $(34.4)$ & $(24.5)$ & $(100.0)$ & 30 \\
\hline \multicolumn{7}{|l|}{ Education } \\
\hline No education/Eleme & ntary ec & lucation & 14 years & $\mathrm{s} *$ & $* * *$ & 15 \\
\hline Elementary 8 years & 0.7 & 31.9 & 39.1 & 28.3 & 100.0 & 239 \\
\hline Secondary, vocat, tec & h 3.6 & 39.2 & 44.5 & 12.7 & 100.0 & 57 \\
\hline Higher education & $(0.0)$ & $(49.1)$ & (31.9) & $(19.0)$ & $(100.0)$ & 47 \\
\hline \multicolumn{7}{|l|}{ Wealth index } \\
\hline The lowest & 0.6 & 39.7 & 40.8 & 19.0 & 100.0 & 77 \\
\hline The second & 41.5 & 40.8 & 17.0 & 0.7 & 100.0 & 77 \\
\hline The middle & 1.7 & 41.0 & 31.1 & 26.2 & 100.0 & 103 \\
\hline The fourth & 3.7 & 23.0 & 39.2 & 34.2 & 100.0 & 55 \\
\hline The highest & 0.0 & 23.0 & 51.9 & 25.1 & 100.0 & 45 \\
\hline Total & 1.3 & 35.8 & 39.1 & 23.8 & 100.0 & 358 \\
\hline
\end{tabular}

Note: Figures in parentheses are based on 25-49 unweighted cases. The sign $\left(^{*}\right)$ indicates that a figure is based on fewer than 25 unweighted cases and has been suppressed.

Source: Demographic and Health Study in Albania, 2008-09, Institute of Statistics, Institute of Public Health, Tirana, Albania \& ICF Macro, Calverton, Maryland, USA, March 2010 
The table above shows the percentage of married women aged 20-24, according to the age difference between the woman and her husband or partner, according to independent factors such as education, place of residence, territory and wealth index. As shown, about one in four married women aged 20-24 have a spouse or partner 10 or more years older and about 39 percent of women aged 20-24 have a spouse or partner 5 to 9 years older (SDSHSH, 2010). But the age difference of 10 years or more between a woman and her spouse or partner is still considered a large age gap in Albania.

The data also show that women aged 20-24 in urban areas are more likely to marry a partner 10 or more years older than rural women ( 26 and 23 percent). Thus there is an increasing positive correlation between age difference between women and men and the urbanization process.

The age difference of 10 years or more between spouses is more common in the Coastal region (32 percent) than in the Mountain region (18 percent). This shows that there is an increasing positive correlation between age difference and social development, emancipation, as well as contact with other cultures and communities. We should keep in mind that coastal areas are among the most developed and advanced areas of the country.

Regarding the impact of education in the marriage age difference, the above data show that women with elementary education are more likely to marry a partner with large age difference, compared to women with higher education. So, the age difference is inversely correlated with the spouses' level of education.

Wealth index, as an independent changer, affects the age difference between spouses. The tables above show that the percentage of married women aged 20-24 with a spouse or partner 10 or more years older is the highest of the three highest wealth indices and lowest for two lowest indices. So, there is a positive correlation between marriages with big age difference and wealth index. In other words, wealth plays a significant role in the age difference between spouses. (Barjaba, 2011a) Also, higher level of youth unemployment compared to adult unemplyment has a significant impact. (Barjaba, 2013)

Furthermore, the percentage of married women aged 20-24, who married men 10 or more years older, from 2005 to 2008-2009 has increased from 20 percent to 24 percent. This shows that increasing age difference between spouses is a trend in recent decades.

\section{The Life Cycle of Women, from Girlhood to the Role of Mother}

According to the Ministry of Health, during 1993-2004 the fertility rate in Albania has decreased from 3.6 to 2.1. This is due to different socio-demographic and economic aspects such as free and uncontrolled population movement, the change of rural/urban population ratio, emigration, especially emigration of young men, economic hardship and unemployment, permission of abortion, family planning etc. In Albania, 1.8 percent of the total population is born every year, 51 percent of whom are male and 49 percent female. Compared to 1994, births in the city have increased by 3 percent, while births in villages have declined by 3 percent.

In the early 1990s in Albania, one in forty teenagers and one in two teenage girls had children (Van der Pol, 1992). The table below gives us a better understanding of this phenomenon.

Table 3: Age of mother and number of births, 1990

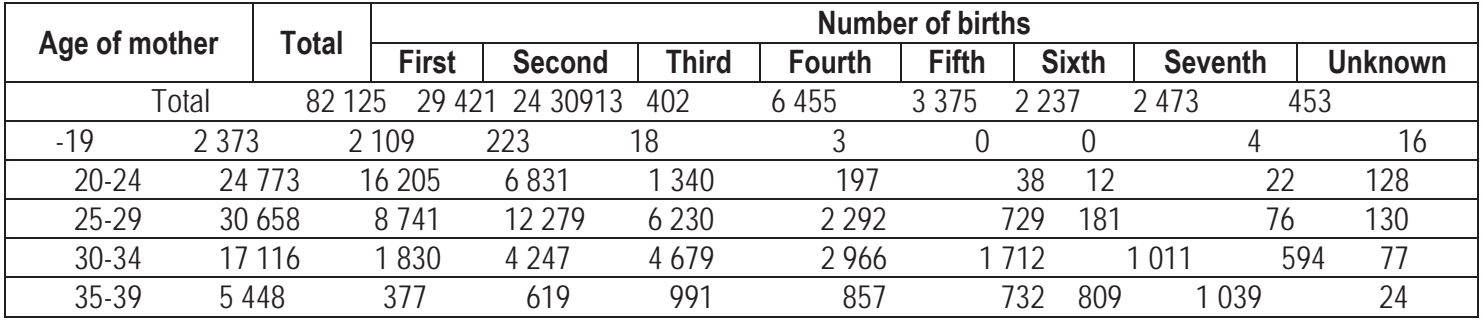

Source: Statistical Yearbook of Albania, 1991. (Partial data)

As seen from the above data, from the women who gave birth, the age group 20-24 comes after the group aged 25-29. The good health of mothers is a condition for the grouwth of healthy babies. This also demonstrates that the women take over the responsibilities of children growth and education at an early age. In the Albanian family, the tradition of taking care of children is generally a mission of mothers. Consequently, women have a heavy burden in the faily life and activities. The difficulties of transition ahave a direct impact to family life and create several family, social and moral 
challenges and implications to new families.

Mothers with one child are on top of the list, women with two children are next, those with three children are the third group. A hidden rule has been infleuncing this situation through spontaneously regulating the marriage annd children growth. This rule was spontaneously reconciliating the old family tradtion with new ones and the real opportunities to meet the new demands of fanily life.

The number of mother with more than one child up to 19 years old was particualrly small, about 11 percent, compared to the numer of mother of this age. This is explained by the massive schooling of Albanian girls. There are two factores which influenced the fall of marriage age of Albanain girls: the increase of economic functions of Albanian families and mass migration of young people. The first factor took the grils out of the school and pushed them to work. The second one simplified the marriage ceremonies.

Although the majority of the women-mothers aged 20-24, about 65.4 percent had only one child, the group of women-mothers, 34.5 percent, that had more than one child is a considerable percentage. About a fifth of them were mothers with three children. These indicators show that women face family problems, such as giving birth and raising children too early. Consequently, women were left out of the job market and their family obligations increased.

Meanwhile, we should also give attention to the birth performance, which during the period 1990-2007 had the following dynamic:

Table 4: Births order in years, 1990-2007

\begin{tabular}{|c|c|c|c|c|c|c|}
\hline Years & & 1990 & 1995 & 2000 & 2005 & 2007 \\
\hline Total & $\begin{array}{l}\mathrm{Nr} \\
\%\end{array}$ & $\begin{array}{c}82,125 \\
100\end{array}$ & $\begin{array}{c}72,081 \\
100\end{array}$ & $\begin{array}{c}51,242 \\
100\end{array}$ & $\begin{array}{c}39,612 \\
100\end{array}$ & $\begin{array}{c}33,163 \\
100\end{array}$ \\
\hline First & $\begin{array}{l}\mathrm{Nr} \\
\%\end{array}$ & $\begin{array}{c}29,421 \\
35.82\end{array}$ & $27,477 \quad 38.12$ & $\begin{array}{c}19,588 \\
38.23\end{array}$ & $\begin{array}{c}16,895 \\
42.65\end{array}$ & $\begin{array}{c}17,537 \\
52.88\end{array}$ \\
\hline Second & $\begin{array}{l}\mathrm{Nr} \\
\%\end{array}$ & $\begin{array}{c}24,309 \\
29.60\end{array}$ & $\begin{array}{c}23,974 \\
33.26\end{array}$ & $\begin{array}{c}17,562 \\
34.27\end{array}$ & $\begin{array}{c}12,314 \\
31.09\end{array}$ & $\begin{array}{l}9,898 \\
29.85\end{array}$ \\
\hline Third & $\begin{array}{l}\mathrm{Nr} \\
\%\end{array}$ & $\begin{array}{c}13,402 \\
16.32\end{array}$ & $\begin{array}{c}11,000 \\
15.26\end{array}$ & $\begin{array}{l}7,824 \\
15.27\end{array}$ & $\begin{array}{l}5,008 \\
12.64\end{array}$ & $\begin{array}{l}3,945 \\
11.90\end{array}$ \\
\hline Fourth & $\begin{array}{l}\mathrm{Nr} \\
\%\end{array}$ & $\begin{array}{c}6,455 \\
7.86\end{array}$ & $\begin{array}{c}4,512 \\
6.26\end{array}$ & $\begin{array}{c}2,651 \\
5.17\end{array}$ & $\begin{array}{c}1,412 \\
3.56\end{array}$ & $\begin{array}{c}1,126 \\
3.40\end{array}$ \\
\hline Fifth & $\begin{array}{l}\mathrm{Nr} \\
\%\end{array}$ & $\begin{array}{c}3,375 \\
4.11\end{array}$ & $\begin{array}{c}1,881 \\
2.61\end{array}$ & $\begin{array}{l}977 \\
1.91\end{array}$ & $\begin{array}{l}466 \\
1.18\end{array}$ & $\begin{array}{l}315 \\
0.95\end{array}$ \\
\hline Sixth & $\begin{array}{l}\mathrm{Nr} \\
\%\end{array}$ & $\begin{array}{c}2,237 \\
2.72\end{array}$ & $\begin{array}{c}923 \\
1.28\end{array}$ & $\begin{array}{l}384 \\
0.75\end{array}$ & $\begin{array}{l}185 \\
0.47\end{array}$ & $\begin{array}{l}120 \\
0.36\end{array}$ \\
\hline Seventh & $\begin{array}{l}\mathrm{Nr} \\
\%\end{array}$ & $\begin{array}{c}2,473 \\
3.01\end{array}$ & $\begin{array}{l}937 \\
1.30\end{array}$ & $\begin{array}{l}364 \\
0.71\end{array}$ & $\begin{array}{l}131 \\
0.33\end{array}$ & $\begin{array}{l}114 \\
0.34\end{array}$ \\
\hline Unknown & $\begin{array}{l}\mathrm{Nr} \\
\%\end{array}$ & $\begin{array}{l}453 \\
0.55\end{array}$ & $\begin{array}{c}1,377 \\
1.91\end{array}$ & $\begin{array}{c}1,891 \\
3.69\end{array}$ & $\begin{array}{c}3,201 \\
8.08\end{array}$ & $\begin{array}{l}108 \\
0.33\end{array}$ \\
\hline
\end{tabular}

Source: Statistical Yearbook of Albania, 1991 \& Statistical Yearbook of Albania from 1998 to 2007, INSTAT, 2010.

As shown, the first birth is constant during the years. The first/second birth ratio is lower in 1990-2000, respectively, 35.8, 29.6, 38.1, 33.3 and 38.2, 34.3, There was a significant increase in 2000-2007, 42.3, 31.1 and 52.9: 29.9. This phenomenon can be explained with the frequency of marriages and first births, as well as self-limitations of the spouses to have a second child, due to new circumstances or the impact of family planning policy. The difference between the frequency of the first birth and third as well as between the second and third birth is increasing, which can also be explained by the above circumstances. While giving birth to four or more children is becoming rare.

The age of mothers affects the health of newborns. To get a complete picture of births by age of mothers, we can look at the following table: 
Table 5: Children born by age of mothers (in percentage)

$\begin{array}{llllllll}\text { Age group in years } & \mathbf{1 9 5 0} & \mathbf{1 9 6 0} & \mathbf{1 9 7 0} & \mathbf{1 9 8 0} & \mathbf{1 9 9 0} & \mathbf{2 0 0 0} & \mathbf{2 0 0 7} \\ \text { Total } & 100 & 100 & 100 & 100 & 100 & 100 & 100 \\ -19 & 4,5 & 6,7 & 5,6 & 4,6 & 2,9 & 4.88 & 5,14 \\ 20-24 & 24,5 & 26,8 & 30,3 & 34,8 & 30,2 & 31.03 & 31,15 \\ 25-29 & 25,5 & 25,1 & 27,2 & 31,1 & 37,3 & 34.56 & 33,33 \\ 30-34 & 20,3 & 18,8 & 19,4 & 17,1 & 20,8 & 19.97 & 19,61 \\ 35-39 & 14,0 & 12,1 & 11,0 & 9,1 & 6,6 & 7.15 & 8,09 \\ 40-44 & 7,2 & 7,1 & 4,6 & 2,9 & 1,6 & 1.44 & 1,67 \\ 45-49 & 2,2 & 2,1 & 1,1 & 0,3 & 0,3 & 0.09 & 0,23 \\ 50+ & 1.0 & 0,8 & 0,3 & 0,0 & 0,0 & 0.02 & 0,07 \\ \text { Unknown } & 0,8 & 0,5 & 0,5 & 0,3 & 0,3 & 0.87 & 0,71\end{array}$

Source: Statistical Yearbook of Albania , 1991 \& Statistical Yearbook of Albania 1998-2007, INSTAT , 2010.

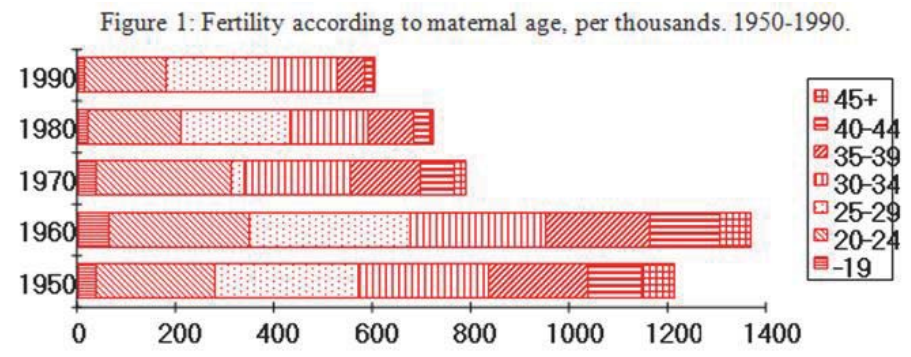

Excluding 1950, we can see that the percentage of mothers under 19 years old is declining. This is due to the mentality change of Albanian women and increased social inclusion. These changes happened as a result of more Albanian women attending high school. The percentage of mothers is lower not only in absolute terms but also relative to other age groups fertility for 1990 . We can notice a trend of women delaying marriages and giving births to children.

The distribution of all women and currently married women, according to fertility rate, the average number of children born and the average number of live births, by age group, is as following:

Table 6: Children born and their survival rate. Percent distribution of all women and currently married women by the number of children born, the average number of children born and the average number of live births, by age group, Albania 2008-2009.

\begin{tabular}{|c|c|c|c|c|c|c|c|c|c|c|c|c|c|c|}
\hline \multicolumn{15}{|c|}{ Number of children borm } \\
\hline Age & & 0 & 1 & 2 & 3 & 4 & 5 & 6 & 7 & 8 & 9 & \multicolumn{3}{|l|}{$10+$} \\
\hline \multicolumn{15}{|c|}{ Total Number of females Average number of children Average number of children born that survive } \\
\hline \multicolumn{15}{|c|}{ ALL FEMALES } \\
\hline $15-19$ & 98.1 & 1.8 & 0.1 & 0.0 & 0.0 & 0.0 & 0.0 & 0.0 & 0.0 & 0.0 & 0.0 & $100.0 \quad 1,478$ & 0.02 & 0.02 \\
\hline $20-24$ & 5.2 & 16.8 & 6.8 & 0.9 & 0.3 & 0.0 & 0.0 & 0.0 & 0.0 & 0.0 & 0.0 & 100.0976 & 0.34 & 0.34 \\
\hline $25-29$ & 36.9 & 19.6 & 32.3 & 9.0 & 1.6 & 0.1 & 0.4 & 0.0 & 0.0 & 0.0 & 0.0 & 100.0848 & 1.21 & 1.18 \\
\hline $30-34$ & 12.0 & 12.8 & 42.2 & 24.0 & 7.1 & 1.4 & 0.5 & 0.0 & 0.0 & 0.0 & 0.0 & $100.0 \$ 66$ & 2.08 & 2.02 \\
\hline $35-39$ & 4.8 & 6.8 & 42.7 & 32.6 & 8.5 & 3.0 & 0.7 & 0.8 & 0.1 & 0.0 & 0.0 & $\begin{array}{lll}100.0 & 1,097\end{array}$ & 2.50 & 2.41 \\
\hline $40-44$ & 4.3 & 6.5 & 37.5 & 31.7 & 13.1 & 4.3 & 1.8 & 0.5 & 0.2 & 0.1 & 0.0 & $100.0 \quad 1,232$ & 2.67 & .58 \\
\hline 45.49 & 3.3 & 5.1 & 33.3 & 31.9 & 14.6 & 6.2 & 3.0 & 1.4 & 0.8 & 0.4 & 0.1 & $100.0 \quad 1,088$ & 2.95 & 2.80 \\
\hline Total & 36.2 & 8.9 & 26.4 & 18.3 & 6.5 & 2.2 & 0.9 & 0.4 & 0.2 & 0.1 & 0.0 & $100.0 \quad 7,584$ & 1.64 & 1.58 \\
\hline \multicolumn{15}{|c|}{ FEMALES CURRENTLY MARRIED } \\
\hline $15-19$ & 76.4 & 22.5 & 1.1 & 0.0 & 0.0 & 0.0 & 0.0 & 0.0 & 0.0 & 0.0 & 0.0 & 100.0110 & 0.25 & 0.25 \\
\hline $20-24$ & 33.5 & 44.8 & 18.5 & 2.4 & 0.7 & 0.0 & 0.0 & 0.0 & 0.0 & 0.0 & 0.0 & 100.0358 & 0.92 & 0.91 \\
\hline $25-29$ & 13.4 & 26.0 & 44.9 & 12.7 & 2.2 & 0.1 & 0.6 & 0.0 & 0.0 & 0.0 & 0.0 & 100.0599 & 1.67 & 1.64 \\
\hline 30-34 & 2.0 & 13.8 & 46.9 & 27.1 & 8.0 & 1.6 & 0.6 & 0.0 & 0.0 & 0.0 & 0.0 & 100.0766 & 2.32 & 2.26 \\
\hline $35-39$ & 1.3 & 6.3 & 44.4 & 34.0 & 9.0 & 3.3 & 0.8 & 0.8 & 0.1 & 0.0 & 0.0 & $100.0 \quad 1,022$ & 2.61 & 2.51 \\
\hline $40-44$ & 1.8 & 5.6 & 38.3 & 33.4 & 13.7 & 4.6 & 1.8 & 0.6 & 0.2 & 0.1 & 0.0 & $100.0 \quad 1,155$ & 2.77 & 2.67 \\
\hline $45-49$ & 2.0 & 4.63 & 3.8 & 33.0 & 15.0 & 6.5 & 3.0 & 0.9 & 0.8 & 0.4 & 0.1 & 100.0993 & 2.98 & 2.83 \\
\hline Total & 7.1 & 12.4 & 38.5 & 27.1 & 9.5 & 3.3 & 1.3 & 0.5 & 0.2 & 0.1 & 0.0 & $100.05,001$ & 2.39 & 2.30 \\
\hline
\end{tabular}

Source: Demographic and Health Survey, 2008-2009, Institute of Statistics, Institute of Public Health, Tirana, Albania \& ICF Macro, Calverton, Maryland , USA, March 2010. 
As we can see from the table above, the difference between married women and all women in the average number of children born and living is about 0.8 children. This difference reflects the high percentage of unmarried young women (1519 and 20-24 years old) which are less exposed to pregnancy. The smaller differences in older ages show the influence of divorces or widowed women in lower fertility. The above table shows that the number of children born is positively correlated with age. Among mothers dominate those with two children (39 percent) compared with those with three children (27 percent) and one child (12 percent). Meanwhile, only 15 percent of currently married women have four children or more (SDSHSH, 2010).

During the period 1960-1980 among women with children, women aged 20-24 were on top of the list, while from 1980 to 1990 and onwards women aged 25-29 were on top. This phenomenon goes in harmony with the declining fertility rate of women aged 19 or younger. We can conclude that fertility rate of women under 24 is decreasing, while the fertility rate for the women aged 25-29 years is increasing. In the past decades, the difference was not significant, (going from two to four percent), while from 1980 to 1990 the change is about six percent.

Considering both groups of younger than 19 years old and 20-24 years old, and the place that mothers of these groups hold, we can see that the indicators are increasing. In 1950, 1960, 1970 and 1980 they were respectively 29, 33.5, 35.9 and 39.4 percent. In 1990 this growth discontinued and started to slightly increase again during the period 2000-2007, 31.03 and 31.15 percent. So, 1990 was considered to be a year of fertility changes. Phenomenology of births by mother's age group reflects the changing dynamics of many factors such as: the extension of teenage period and the period of women's education, higher marriage age, better social inclusion, lower fertility rates, and lower number of children per family.

Analysis of these indices and their trends in 1990-2007, show that youths have started to worry about family problems and raising children. This trend was also the same during the period before 1950, which shows a repetition of some demographic phenomena.

According to the fertility rates, the number of mothers under 20 years old giving birth is declining. This decline is not happening to other age groups. From 1950 to 1990, fertility rates for age groups above have fallen respectively 2.5, 1.4, 1.4, 2, 3.6 and 6.4 times. Meanwhile, from 2000 to 2007, these rates have increased, 4.88 and 5.14 percent. Birth rates for mothers under 20 years old are lower only when compared to those of mothers over 40 years old. The decline in birth rates for ages younger than 20 and older than 40 can considered as a normal performance of demographic developments. We should keep in mind the lack of cultural and sexual health education for the group under 20 years old, and the weakening of physiological and health status of women older than 40 years old.

\section{Theoretical Sources}

This article is based on theoretical and documentary sources. Regarding the theoretical sources I rely on several studies conducted from well known Albanian researchers which include issues such as family, marriage and gender during the transition. Regarding the documentary sources I rely on the Statistical Yearbook of Albania, the official publications of the Albanian Institute of Statistics, INSTAT, "The Demographic and Health Survey, 2008-09, Institute of Statistics, Institute of Public Health, Tirana, Albania \& ICF Macro, Calverton, Maryland, USA, March 2010 ".

\section{Research Methodology}

For this article I have used the following methods: i) analysis of existing data and ii) interviews as an instrument of sociological research. These two methods gave me the opportunity to combine the use of existing sources and documents with research elements in the field, such as interviews with persons of institutions dealing with family and marriage.

\section{Conclusions and Recommendations}

Economic and cultural changes have influenced in the change of marriage age. In the last two decades there is a decline in the number of marriages of girls in the age group, 19-29 years, and a slight increase in the number of marriages of girls older than 29 years. "The weight of gravity" of men marriages is shifting gradually out of the youth age. Even within the youth age, the majority of the marriages are created during the "second phase", in the age group 20-24 years, which is consistent with the general tendency to delay marriage age. The marriage age for women is increasing, mainly for the same reasons that marriage age for men increases. 
However, during the last two decades the average age of first marriage for men in Albania has been lower than all Western countries, excluding the United States. While the average age of first marriage for women in Albania has been lower than in western countries.

Increasing age differences between spouses is the marriage trend in the recent decades. The age difference between women and men is in positive correlation with the process of urbanization, social development, as well as interaction with other cultures and communities. But the age difference is negatively correlated with the level of spouses' education. Marriages of spouses with large age differences are positively correlated with wealth index.

Excluding 1950, we can see that the percentage of mothers youner than 19 years old is declining. This is explained by the gradual change of mentality of Albanian women, better social inclusion, and more years of education, as a result of the massive attendance of high school. The number of children born is in positive correlation with the age of women. Among women with children dominate those with two children compared to those with three and one child.

Changes in fertility rate by age group, which began in 1990 have showed the changing dynamics of several factors: longer adolescence phase and female education period, increasing age of marriage, greater involvement in social and public life, and reduction of the number of children per family etc.

These phenomena impose changes in social, gender and health policies of the country.

\section{References}

Barjaba, K. (2013) Kurthet e Papunesise (Unemployment Pitfalls) Tirana: UET Press;

Barjaba, K. (2011a) Elita demografike ne tranzicionin demografik. rinia si pervoje sociologjike (Demographic elite in the demographic transition: Youth as a sociological experience), Tirana: Toena \& UMSH Press;

Barjaba, K. (2011b) As lokale, as kozmopolite? Emigrimi si pervoje sociologjike (Neither locals, nor cospolits: Migration as a sociological experience), Tirana: Toena \& UMSH Press;

Girard, A. (1974) Le choix du conjoint. Paris;

SDSHSH (2010) Demographic and Health Survey, 2008-09, Institute of Statistics, Institute of Public Health, Tirana, Albania \& ICF Macro, Calverton, Maryland, USA;

Van der Pol, H.1992 Age and sex structure of the 1989 census population. (Preleminary analysis) Mimeo for the Republic of Albania, Ministry of Economy and Finance, Department of Statistics;

Statistical Yearbook of Albania, INSTAT, Tirana, 1991;

INSTAT, 1998-2007, 2010 Tirana, 2012. 
